\title{
Long-term treatment of multiple sclerosis with azathioprine
}

\author{
W. R. SWINBURN AND L.A. LIVERSEDGE
}

From the Department of Neurology, The Royal Infirmary, Manchester

SUMMARY Nineteen patients with multiple sclerosis were treated with azathioprine for two years. There was no evidence that treatment prevented deterioration or reduced the number or severity of the relapses when compared with 24 control patients observed over the same period.

There have been several reports of the effect of immunosuppressive drugs on multiple sclerosis (Corley, Lessner, and Larsen, 1966; Cendrowski, 1969; Tucker and Kapphahn, 1969; Cendrowski, 1971). However these reports have been based on small numbers of patients and often no controls have been used or the effect of the drug has been assessed by the improvement or deterioration in the patient's condition over a period of months. The assessment of treatment in multiple sclerosis is notoriously difficult because of the natural history of the disease. We believe that the most reliable guide to the effectiveness of treatment is to compare the number of relapses occurring over the observed period in treated and control groups. We report here a controlled trial of the effect of azathioprine on the relapse rate in multiple sclerosis.

\section{METHOD}

In view of the possible teratogenic effects of azathioprine, women were excluded from the trial. Men with diabetes mellitus, liver, or renal disease were also ? excluded. Only patients able to walk with or withouf $\overrightarrow{.}$ walking aids were included. All patients fulfilled $\vec{N}$ McAlpine's criteria of definite multiple sclerosis $\vec{\Phi}$ that is, a history of an acute retrobulbar neuritis of an episode of paraesthesia, motor weakness, double vision, unsteadiness in walking, or other symptonts known to occur in multiple sclerosis which tended to improve or clear up, followed by one or more relapses during the course of years, with, in addition, these presence of pyramidal tract or other signs indicative of multiple lesions in the central nervous system (McAlpine, Lumsden, and Acheson, 1968).

After consenting to take part in the trial patients were allocated to control or treatment groups in balanced pairs, using a system of subgrouping, to

TABLE 1

MEAN SCORES AT BEGINNING AND AFTER ONE AND TWO YEARS OF TRIAL

\begin{tabular}{|c|c|c|c|c|c|c|}
\hline \multirow[t]{2}{*}{ Parameter } & \multicolumn{2}{|c|}{ At commencement } & \multicolumn{2}{|c|}{ After 1 year } & \multicolumn{2}{|c|}{ After 2 years } \\
\hline & $\begin{array}{c}\text { Control } \\
\text { mean }\end{array}$ & $\begin{array}{c}\text { Treated } \\
\text { mean }\end{array}$ & $\begin{array}{l}\text { Control } \\
\text { mean }\end{array}$ & $\begin{array}{c}\text { Treated } \\
\text { mean }\end{array}$ & $\begin{array}{c}\text { Control } \\
\text { mean }\end{array}$ & $\begin{array}{c}\text { Treated } \\
\text { mean }\end{array}$ \\
\hline Functions & & & & & & \\
\hline Pyramidal & $2 \cdot 04$ & $2 \cdot 47$ & $2 \cdot 00$ & $2 \cdot 53$ & $2 \cdot 16$ & $2 \cdot 74$ \\
\hline Cerebellar & 1.00 & $1 \cdot 11$ & 0.56 & 0.95 & 0.72 & $1 \cdot 05$ \\
\hline Brain-stem* & 0.60 & $1 \cdot 21$ & $0 \cdot 36$ & 0.74 & 0.52 & 0.89 \\
\hline Sensory & 0.80 & 0.95 & 0.76 & 0.58 & $0 \cdot 80$ & 1.00 \\
\hline Bladder and bowel & 0.40 & 0.47 & 0.44 & 0.37 & $0 \cdot 36$ & 0.53 \\
\hline Visual & .52 & $2 \cdot 58$ & 1.48 & $2 \cdot 53$ & $1 \cdot 48$ & $2 \cdot 53$ \\
\hline Mental & 0.00 & 0.00 & 0.00 & $0 \cdot 00$ & 0.00 & 0.00 \\
\hline Other & 0.00 & 0.00 & 0.00 & 0.00 & 0.00 & 0.00 \\
\hline
\end{tabular}

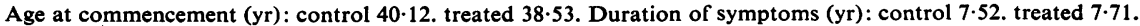
$* \mathbf{P}<0.01$. 
TABLE 2

INCIDENCE OF RELAPSES DURING YEARS ONE AND TWO OF TRIAL

\begin{tabular}{|c|c|c|c|c|c|c|c|c|c|c|c|}
\hline \multicolumn{4}{|c|}{ Relapses during year 1} & \multicolumn{4}{|c|}{ Relapses during year 2} & \multicolumn{4}{|c|}{ Relapses over the 2 years } \\
\hline $\begin{array}{c}\text { Relapses } \\
\text { (no.) }\end{array}$ & Controls & Treated & Total & $\begin{array}{l}\text { Relapses } \\
\quad \text { (no.) }\end{array}$ & Controls & Treated & Total & $\begin{array}{l}\text { Relapses } \\
\quad \text { (no.) }\end{array}$ & Controls & Treated & Total \\
\hline \multirow[t]{3}{*}{2} & $\begin{array}{r}15 \\
7 \\
3\end{array}$ & $\begin{array}{r}15 \\
3 \\
1\end{array}$ & $\begin{array}{r}30 \\
10 \\
4\end{array}$ & $\begin{array}{l}0 \\
1 \\
2\end{array}$ & $\begin{array}{r}21 \\
3 \\
1\end{array}$ & $\begin{array}{r}17 \\
2 \\
0\end{array}$ & $\begin{array}{r}38 \\
5 \\
1\end{array}$ & $\begin{array}{l}0 \\
1 \\
2 \\
3\end{array}$ & $\begin{array}{r}14 \\
6 \\
3 \\
2\end{array}$ & $\begin{array}{r}13 \\
5 \\
1 \\
0\end{array}$ & $\begin{array}{r}27 \\
11 \\
4 \\
2\end{array}$ \\
\hline & 25 & 19 & 44 & & 25 & 19 & 44 & & 25 & 19 & 44 \\
\hline & \multicolumn{3}{|c|}{$\chi_{2}^{2}=1.824 \mathrm{~ns}$} & \multicolumn{4}{|c|}{$\chi^{2}{ }_{2}=0.813 \mathrm{~ns}$} & \multicolumn{4}{|c|}{$\chi^{2}{ }_{2}=2.346 \mathrm{~ns}$} \\
\hline
\end{tabular}

ensure that the two groups would be eventually comparable. The patients were not told to which group they had been allocated.

At the start of the trial, and on subsequent occasions whenever they were examined, all the patients were scored on the Kurtzke scale which was modified slightly from the original for visual acuity (Kurtzke, 1961).

The control group were given $50 \mathrm{mg}$ ascorbic acid a day.

The treatment group before the start of azathioprine had liver function tests, blood urea, urine examination, chest radiograph, and full blood counts and thereafter a haemoglobin estimation, white blood count, and a blood film were checked initially at weekly intervals, and later at monthly intervals. The dose of azathioprine used was $2.5 \mathrm{mg} / \mathrm{kg}$.

A relapse was defined as the onset of new symptoms, persisting for more than 48 hours. Both groups contacted us directly if they developed any new symptoms and were thus seen and examined at the onset of the relapse, and if necessary were visited at home. In an attempt to see if there was any difference in the severity or duration of relapses between the treated and control groups, a scoring system was used also for the relapses as follows:

Paraesthesiae or dysaesthesia: one per limb per week; weakness, clumsiness, or ataxia: three per limb per week; retention of urine: four per week; vertigo, facial pain, facial palsy, oculomotor paresis, dysarthria, dysphagia, or anosmia: three per week; diplopia, 'blurred vision': one per week; retrobulbar neuritis: three per week (Millar, Vas, Noronha, Liversedge, and Rawson, 1967).

\section{RESULTS}

Table 1 shows the mean Kurtzke scores for both groups at the start of the trial and at one and two year intervals. Apart from a slightly worse score for brain-stem function in the treated group, there is no statistical difference between the groups whose average age and duration of symptoms is also comparable.

Table 2 shows the number of relapses and

TABLE 3

RELAPSE SCORES IN TWO GROUPS

\begin{tabular}{|c|c|c|c|c|}
\hline & \multicolumn{2}{|c|}{ Year 1} & \multicolumn{2}{|c|}{ Year 2} \\
\hline & Control & Treated & Control & Treated \\
\hline $\begin{array}{l}\text { Patients who } \\
\text { relapsed (no.) } \\
\text { Mean score }\end{array}$ & $\begin{array}{l}10 \\
25 \cdot 0\end{array}$ & $\stackrel{4}{41 \cdot 5}$ & $\begin{array}{c}4 \\
39 \cdot 0\end{array}$ & $\begin{array}{c}2 \\
30 \cdot 0\end{array}$ \\
\hline$t$ & \multicolumn{2}{|c|}{$1.084 \mathrm{NS}$} & \multicolumn{2}{|c|}{$0.643 \mathrm{NS}$} \\
\hline
\end{tabular}

Table 3 the relapse scores in the two groups for the observed two year period.

The Tables show no evidence to suggest that the treated group do better than the controls, either from the point of view of deterioration or reduction in the number or severity of relapses.

\section{DISCUSSION}

Four patients in the treated group withdrew because of gastrointestinal upset associated with the azathioprine (nausea, vomiting, and abdominal pain). One patient withdrew from each group because they left the area. These six patients are not included in the analysis. 
Initially the azathioprine was dispensed as a single total daily dose and, if the patient complained of any gastrointestinal tract upset, he was advised in the first instance to divide the dose and to take it after meals; if he continued to have symptoms he was then advised to take the total dose of the drug immediately before going to bed, and this in our experience seems the best way of avoiding gastrointestinal upset with azathioprine.

At the beginning, we were rather worried that there might be a problem with infections in the treated group, but we have had no major infections at all. Only two patients showed a depression of the white count and this was of gradual onset over several weeks; the azathioprine was stopped when the white count fell below 3,600 per c.mm and within a fortnight the blood counts had returned to normal and the azathioprine was resumed.

We wish to thank the Multiple Sclerosis Society of Great Britain and Northern Ireland who provided financial support and the Wellcome Research Laboratories who generously supplied the azathio- prine without restriction and without charge. We feel we should also record our appreciation of the splendid cooperation given to us by our patients in this trial.

\section{REFERENCES}

Cendrowski, W. S. (1969). Multiple sclerosis; a therapeutic trial of immunosuppressants. Schweizes Archiv für Neurologie, 105, 241-246.

Cendrowski, W. S. (1971). Therapeutic trial of Imuran (azathioprine) in multiple sclerosis. Acta Neurologica Scandinavica, 47, 254-260.

Corley, C. C., Jr., Lessner, H. E., and Larsen, W. E. (1966). Azathioprine therapy of 'autoimmune' diseases. American Journal of Medicine, 41, 404-412.

Frick, E., Angstwurm, H., and Späth, G. (1971). Immunosuppressive Therapie der multiplen Sklerose. Münchener medizinische Wochenschrift, 113, 221-231.

Kurtzke, J. F. (1961). On the evaluation of disability in multiple sclerosis. Neurology (Minneap.), 11, 686-694.

McAlpine, D., Lumsden, C. E., and Acheson, E. D. (1968). Multiple Sclerosis-An Appraisal, p. 183. Livingstone: Edinburgh.

Millar, J. H. D., Vas, C. J., Noronha, M. J., Liversedge, L. A., and Rawson, M. D. (1967). Long-term treatment of multiple sclerosis with corticotrophin. Lancet, 2, 429-431.0

Tucker, W. G., and Kapphahn, K. H. (1969). A preliminar evaluation of azathioprine (Imuran) in the treatment of multiple sclerosis. Henry Ford Hospital Medical Bulletir(⿻丅⿵冂⿰⿱丶丶⿱丶丶⿰木口⿻ 17, 89-92. 